\title{
GEMOX-B Regimen
}

National Cancer Institute

\section{Source}

National Cancer Institute. GEMOX-B Regimen. NCI Thesaurus. Code C161970.

A chemotherapy regimen consisting of gemcitabine, oxaliplatin, and bevacizumab that may be used in the treatment of certain liver and pancreatic cancers. 